\title{
Revolucionarios y realistas en la provincia de Tunja
}

I S I D RO VA NEGAS Y MAGALI CARRILLO

Bogotá: Ediciones Plural

2020 | ISBN: 978-958-48-8893-8 | $180 \mathrm{pp}$.

DOI: https://doi.org/10.22380/20274688.1272

ontrariamente a algunas voces que consideran que el periodo de Independencia de Colombia ha sido suficientemente abordado, lo que en realidad han demostrado los libros y los artículos publicados en el marco de estos años conmemorativos del Bicentenario es que, si bien se han llenado algunos vacíos, aún está pendiente el reto de cubrir nuevas temáticas o revaluar otras tantas.

Desde esa perspectiva, hay todavía mucho que escudriñar en torno a cómo se vivió esa fase crucial de la historia nacional. El libro publicado por los historiadores Isidro Vanegas y Magali Carrillo apunta de manera especial a constatar cuán importante es reorientar el foco de atención en la elaboración o reconstrucción del complejo entramado a escala regional. En ese sentido, el compromiso es de mayúsculas proporciones por cuanto habría que emprender esa apuesta en las áreas donde se vivió de una manera más intensa la convulsión política y la lucha militar (como en las provincias de Bogotá, Tunja, Socorro, Antioquia, Santa Marta, Cartagena y Popayán), así como también adentrarse en sondear el devenir de la guerra y de sus múltiples efectos en zonas periféricas o apartadas del conflicto. Dentro de ese propósito, el primer llamado que hacen los autores es a reconocer y reflexionar sobre lo sucedido en la provincia

I Si bien es cierto que aún resulta muy prematuro hacer un balance de la producción historiográfica del Bicentenario de la Independencia, es válido tener de referencia algunas reflexiones iniciales. Véase Reyes; Tabanera; Pérez. 
de Tunja y no circunscribirse únicamente a los hechos transcurridos en la capital neogranadina.

Dentro de esa reivindicación historiográfica, se recuerda cómo la provincia de Tunja fue el epicentro de dinámicas transcendentales como la promulgación de la primera Constitución republicana o la sede del Congreso de las Provincias Unidas. Esto implica, desde luego, centrarse en estos procesos y reconocer en ellos la participación de la abigarrada sociedad de entonces, no solo glorifica$\mathrm{da}$ con hombres blancos y nobles, sino matizada con todos sus actores y, con ellos, sus intereses, sus expectativas y sus frustraciones. Entender, por ejemplo, que la provincia de Tunja no fue solo el espacio por donde transitó la campaña libertadora, sino también ver cómo el invaluable apoyo de sus pobladores fue decisivo para el triunfo militar coronado en los campos del puente de Boyacá el 7 de agosto de I8I9 y afianzado días después con la ocupación de la ciudad de Santafé. Son esos campesinos, artesanos, comerciantes, mujeres, sirvientes y demás gentes del común los que merecen ser visibilizados como sujetos que hicieron parte de la historia provincial. Es allí donde debe estar el énfasis investigativo y no en personajes ficticios sobredimensionados por algunos académicos aficionados que aún hoy siguen empeñados en crear falsos hitos y referentes de la historia regional sin el suficiente sustento documental.

Es también un objetivo de los autores ahondar en la impronta de aquellos sujetos y sucesos que transcurrieron en el ámbito provincial, pero no inmersos de manera aislada en sus espacios locales, sino conectados con una realidad más amplia vivida en el resto del territorio neogranadino. El mismo título del libro anuncia su intención de trazar una mirada completa sobre el proceso de independencia en la provincia de Tunja, en la que se logre superar y avanzar más allá de la limitada percepción triunfalista y heroica propia de la historiografía tradicional. La idea es abordar esta etapa revolucionaria sin apasionamientos ni sesgos y con la posibilidad de sopesar ponderadamente tanto las fuentes documentales de origen patriota como las de origen español.

Dentro de esos propósitos, el libro reúne dos estudios, el primero de los cuales está construido a partir de una juiciosa revisión de fuentes primarias, tales como periódicos, impresos y manuscritos de archivo hallados principalmente en el Archivo Regional de Boyacá y en el Archivo General de la Nación. Al final, se incluyó una selección de doce documentos transcritos a manera de complemento.

En ese primer aparte, Vanegas explica la restauración monárquica en la provincia de Tunja desde tres perspectivas de análisis. En la primera se ocupa 
de los efectos desgastantes del primer experimento revolucionario que provocó un clamor por el restablecimiento del antiguo orden. La segunda corresponde a la encrucijada en la que se vieron envueltas las autoridades españolas que, si bien estaban empeñadas en reforzar los niveles de lealtad a un sistema monárquico proteccionista y magnánimo, en la práctica debieron gobernar en medio de limitaciones presupuestales y administrativas, ante lo cual adquirió mayor preponderancia el estamento militar que debió desplegar su dureza y poderío para contener los brotes de resistencia social. Finalmente, y como consecuencia de todo lo anterior, desde la tercera perspectiva se examinan los cambios suscitados en la reacción popular que pasó del respaldo inicial al creciente inconformismo por cuenta de los excesos en las contribuciones y la reiterada aplicación de mecanismos de coerción por parte del gobierno español, a todo lo cual se le sumó la restricción en los canales de expresión impresa y en los espacios públicos de discusión.

Con estos tres elementos de análisis se intenta repensar la Reconquista ${ }^{2}$, no solo como el discurso institucional y las medidas implementadas oficialmente por los gobernantes, sino vista también desde abajo, es decir, desde la percepción y las reacciones suscitadas en la población local. Este componente social aporta claves que son fundamentales para entender por qué la campaña de liberación de la zona central de la Nueva Granada, más allá de considerarse un triunfo militar forjado mediante estrategias militares suficientemente estudiadas por los historiadores de primera generación, fue además el resultado del fracasado intento por restaurar el régimen monárquico y de las esperanzas que empezaron paulatinamente a aglutinarse en torno a los gestores del movimiento revolucionario y a las fuerzas patriotas de los Llanos como deseada alternativa de cambio.

El autor no se detiene en los excesos del poder coercitivo que se observaron durante aquellos años, cuya temática se ha constituido en el eje tentador de buena parte de los estudios sobre el proyecto pacificador, sino que explora el trasfondo social del cúmulo de retaliaciones y el deterioro de las condiciones económicas de los habitantes de la provincia, cada vez más empobrecidos y abatidos por tener que sostener bajo presión a las tropas realistas que operaban allí, una carga adicional a las habituales imposiciones tributarias que regían en tiempos anteriores del dominio hispánico.

2 Sobre una novedosa mirada a esta fase del proceso de Independencia, véase Gutiérrez. 
En resumidas cuentas, el método de análisis empleado en esta primera parte del libro abre la invitación a emprender investigaciones que indaguen más allá de la dimensión militar y que aborden de una manera más profunda las implicaciones sociales, políticas y económicas. Apunta también el autor a remarcar en el historiador la importancia de ser consciente de la complejidad de la sociedad existente en aquel periodo de lucha revolucionaria, una sociedad muy lejos de ser homogénea y estática en sus preferencias políticas, opiniones y conductas.

En el segundo estudio, a cargo de Magali Carrillo, se trata el tema de una supuesta conspiración de un grupo de chicheras contra algunos integrantes de la tropa patriota a su paso por Sogamoso en I820. Las primeras denuncias hacían pensar que los soldados habían sido intencionalmente envenenados en una de las chicherías de aquella ciudad, en la que todavía persistían ciertas simpatías hacia las banderas del rey. Esto abrió campo a un extenso juicio y a varios interrogatorios, cuyas incidencias la autora rastrea mediante la consulta de los documentos que reposan en el Archivo General de la Nación, complementado esto con datos obtenidos en archivos regionales, los informes de gobierno y el cruce epistolar sostenido por los máximos dirigentes republicanos.

Para el presidente Simón Bolívar era de suma importancia aclarar este asunto en momentos en los cuales se estaban formando los ejércitos para defender la zona central del altiplano y lanzar la ofensiva de liberación en otras áreas de la Nueva Granada. Por ello, se desplegó la máxima atención y alarma al adoptarse medidas de precaución en un territorio en el que, aun cuando se creía totalmente redimido del dominio español, a decir verdad apenas se estaba afianzando y entronizando el proyecto republicano en el común de las gentes. El hecho suscitó una serie de sospechas, rumores y no pocas desconfianzas pero, a fin de cuentas, se comprobó que en realidad el origen de la mortandad de la tropa se debió a las inapropiadas condiciones de salubridad y no a un acto conspirativo.

En su minuciosa revisión y comprensión de los documentos consultados, la autora advierte de las precarias condiciones sociales de los militares patriotas y pone de relieve varios detalles de la vida social y cotidiana de entonces, así como también la intrincada dinámica de las lealtades a escala local, pero quizá el principal aporte de este trabajo es que deja al descubierto una faceta distinta de la mujer en el marco de las guerras de independencia y revela en cierto sentido su cotidianidad y sus alternativas de supervivencia económica. Es este precisamente el acento que nuevos estudios han pretendido imprimir a 
este tema del papel de las mujeres en la guerra, no únicamente el estereotipo de las heroínas sino el de las mujeres del común sobre las cuales también se sintieron los avatares de la agitación política propia de esta época.

Carrillo no se limita a plasmar en su trabajo la rica información que brindan las incidencias de aquel hecho sucedido en Sogamoso, sino que indaga en los antecedentes y en el contexto de esa ciudad y en los acontecimientos allí vividos desde las primeras manifestaciones revolucionarias, todo esto para subrayar la heterogeneidad de fuerzas e intereses que estuvieron en juego y las disputas locales por el poder. La transcripción de una serie de documentos contribuye a ilustrar de una manera más detallada estas dinámicas.

Por otro lado, el estudio presentado por Carrillo arroja interesantes luces sobre las relaciones entre los integrantes del estamento militar y la comunidad, un asunto muy poco abordado y del cual no es fácil hallar pistas esclarecedoras en el intercambio epistolar y en los informes militares. Es esta una interacción que tiene hondas raíces en esta última fase del periodo de la guerra, en la cual las ingentes demandas de pie de fuerza comprometieron a un considerable número de pobladores. Finalmente, la autora pone en evidencia cómo la dimensión política y la militar adquirieron un lugar de preponderancia y lograron influir prácticamente en todos los segmentos de la sociedad, incluso en los sectores populares durante aquellos tiempos en que se estaban cimentando las bases de la naciente república.

Al examinar de nuevo el libro en su conjunto, se constata la intencionalidad de inscribirlo dentro de las recientes tendencias historiográficas, constituyéndose en un claro recordatorio de los desafíos que el mundo académico tiene por delante más allá de la rimbombante conmemoración militar de los doscientos años de la batalla de Boyacáa, en especial el de aventurar nuevas miradas a las fuentes primarias, en las cuales es posible encontrar sugestivos e insospechados rastros con los que pueda armarse el intrincado mosaico del proceso de la Independencia a escala regional.

3 Sobre nuevas miradas a la campaña libertadora, vale destacar otro libro recientemente publicado por el autor. Véase Vanegas. 


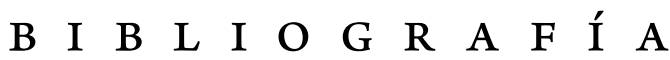

Gutiérrez Ardila, Daniel. La Restauración en la Nueva Granada (I8I5-I819). Bogotá: Universidad Externado de Colombia, 2016.

Pérez Herrero, Pedro. "Las independencias americanas. Reflexiones historiográficas con motivo del Bicentenario". Cuadernos de Historia Contemporánea, n. ${ }^{\circ}$ 32, 2010 , pp. 5 I-72.

Reyes Cárdenas, Catalina. "Balance y perspectivas de la historiografía sobre Independencia en Colombia”. Historia y Espacio, vol. 5, n. ${ }^{\circ} 33,2009$, pp. 15-40.

Tabanera García, Nuria. "Pensar hoy el Bicentenario: sobre las dimensiones actuales de la revoluciones por la Independencia de América Latina”. Amérique Latine Histoire et Mémoire, n. ${ }^{\circ}$ 19, 2010, pp. I-10.

Vanegas Useche, Isidro. Las batallas de Boyacá. Hombres, mujeres, experiencias. Bogotá: Ediciones Plural, 2019. 